\title{
P53 PROTEIN EXPRESSION IN EPITHELIAL LINING OF ODONTOGENIC CYSTS: AN IMMUNOHISTOCHEMICAL DESCRIPTIVE CASE STUDY
}

\author{
Aqib Sohail ${ }^{1}$, Aneela Amjad ${ }^{2}$, Nighat Zahid ${ }^{3}$, Asad Aizaz Chatha ${ }^{4}$, Nauman Rauf Khan ${ }^{5}$, Aamer lqbal $^{6}$, \\ Bilal Yousuf $^{7}$
}

\section{ABSTRACT:}

OBJECTIVES:

The current study was conducted to analyze immunohistochemical appearance of P53 protein in odontogenic cysts.

\section{METHODOLOGY:}

Thirty paraffin blocks of confirmed case were prepared to investigate the immunohistochemical appearance of $P 53$ protein.

\section{RESULTS:}

Sixteen out of thirty odontogenic cysts (53.3\%) showed P53, four out of ten dentigerous cyst (40\%) had P53, twelve out of fifteen odontogenic keratocysts (80\%) expressed P53 while none of the five radicular cysts (0\%) showed $P 53$ protein.

\section{CONCLUSION:}

Reclassification of OKC as keratocystic odontogenic tumor was supported by the present study and its findings.

KEYWORDS: P53, Odontogenic Cysts, Dentigerous Cysts, Radicular Cysts, Odontogenic Keratocysts

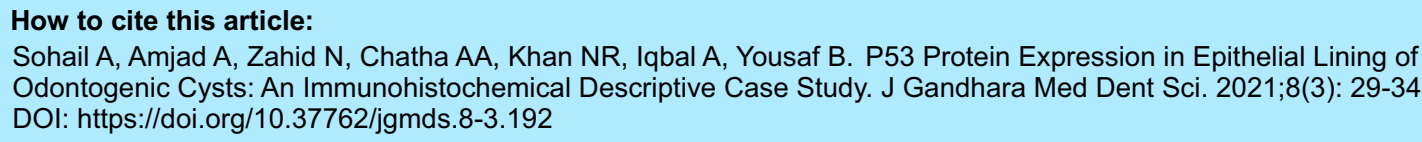

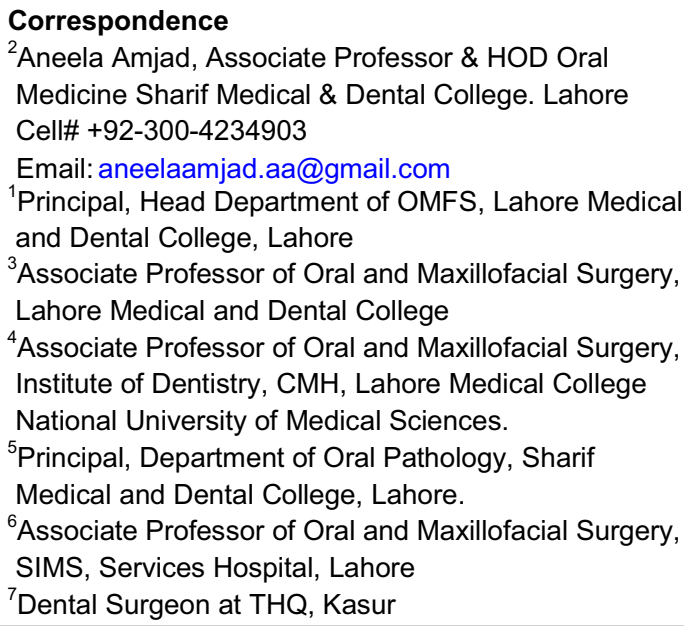

\section{INTRODUCTION.}

True Cyst is defined as a pathological cavity enveloped by an epithelial tissue membrane with liquid, semi liquid or gaseous contents ${ }^{1}$. Pathogenesis of cystic development includes fluid accumulation within the cyst along with connective tissue capsule and epithelial lining proliferation. The growth of cyst is also affected by bone resorbing factors, such as prostaglandins $^{2}$. Odontogenic cysts are derived into the jaws from odontogenic remnants and are the second most common lesions in the oral and maxillofacial region ${ }^{3}$. Seven to $12 \%$ of oral and maxillofacial biopsies diagnosed are odontogenic cysts according to 
the results of different studies ${ }^{4}$. Most common cyst among all odontogenic cysts is radicular cyst $(50.7 \%)$, followed by the dentigerous (follicular) cyst $(18.5 \%)$ and odontogenic keratocyst (14.3\%). Radiographically, all odontogenic cysts present with $100 \%$ radiolucency excluding calcified odontogenic cyst, which presents $77 \%$ radiolucency and $23 \%$, mixed behavior according to the results of recent study ${ }^{5}$. Approximately 1-2/1000 of carcinomas arising in odontogenic cysts was reported in the literature. Odontogenic keratocyst and dentigerous cysts are considered to be highest in neoplastic transformation among all of the odontogenic cysts $^{6}$. Results of literature show transformation of dentigerous cyst into ameloblastoma and odontogenic keratocyst into squamous cell carcinoma ${ }^{7,8}$. The P53 gene on chromosome 17 is a tumor suppressor gene, its mutation is common in a variety of human tumors and is considered to be a common step in neoplastic transformation. P53 over expression is associated with higher dysplastic changes and loss of differentiation during the development of oral malignancy according to the results of studies on pre neoplastic and neoplastic lesions of the oral mucosa. Inactivation of P53 is involved in both initiation and progression of odontogenic cysts ${ }^{9}$. Half-life of P53 gene is extended due to mutations of TP53 gene, which results in increased concentration of P53, which might be due to association of wild type P53 with other proteins, or disruption of its degradation pathway. Half-life of P53 is 20 minutes $^{10}$. Half-life of P53 protein in normal cells is bit shorter, that is why it cannot be detected immunohistochemically. On the other hand, mutation in P53 gene is associated with increased stability and over expression of P53 protein $^{7}$. Many studies shows among all the odontogenic cysts, odontogenic keratocyst shows increased expression of P53 which appears to have specific lining epithelium with an intrinsic growth potential resulting in marked tendency to recur ${ }^{9}$. World Health Organization has reclassified it as Keratocystic Odontogenic Tumor owing to its aggressive, infiltrative behavior ${ }^{11}$. Aim of this study is to find out the percentage of cells expressing P53 gene in epithelial lining of different types of odontogenic cysts by using immunohistochemical analysis in our population. No local published evidence proved that previously any study of the same nature was carried out in Pakistan to find out P53 expression in all diverse biopsy proven cases of odontogenic cysts. This is the first study that was conducted in Pakistan to find out percentage of P53 gene in odontogenic cysts. Internationally, there is contradiction in reported percentages of $\mathrm{P} 53$, which ranges from $0-67.5 \%{ }^{12}$. Fifty One studied samples, odontogenic cysts and tumors did not reported presence of $\mathrm{P}_{53}{ }^{12}$. A study reported $67.5 \%$ expression of P53 in odontogenic cysts, ${ }^{9}$ in contrast to the other study reported $33.3 \%$ expression $^{10}$. Bagulkar et $\mathrm{al}^{7}$, reported P53 expression in $29 \%$ odontogenic keratocyst, $26 \%$ radicular cyst and $15 \%$ dentigerous cyst cases, while in another study percentage of P53 expression was $81.8 \%, 33.3 \%$ and $0 \%$ for odontogenic keratocyst, dentigerous cyst and radicular cyst, respectively ${ }^{10}$. The objective of this study is to find out the percentage of cells expressing P53 gene in epithelial lining of different types of odontogenic cysts by using immunohistochemical analysis in our population.

\section{METHODOLOGY:}

This descriptive case study included those patients who reported to the department of Oral and Maxillofacial Surgery, Lahore Medical and Dental College, Lahore, Pakistan during 20182020 presented with radiolucent lesions of jaws radio graphically. Thirty patients of odontogenic cysts were taken by using $33.3 \%$ expected frequency of P53 gene in odontogenic cyst cases with 95\% confidence level and 10\% absolute precision. The sampling technique used in this study is non-probability, purposive sampling. The inclusion criteria; both genders (male/female) of any age, having radiolucent lesions of jaws, and lesion more than $5 \mathrm{~mm}$ (assessed radiographically) were included in the study. Infected cases (e.g. periapical abscess) assessed clinically as presence of draining pus were excluded from the study. After ethical approval by local research and ethic committee of Lahore Medical and Dental College, Lahore, 30 patients of odontogenic cysts fulfilling the criteria were enrolled in this study. Demographic history (name, age, gender) was taken from the patient, after an informed consent. The surgical site was prepared for 1 minute with $0.12 \%$ chlorhexidine oral rinses, and $7.5 \%$ pyodine solution was 
used externally for extraoral lesions under absolute sterile conditions keeping the surgical site isolated to avoid contamination. Wound was closed after specimen was taken. Specimen was fixed with $10 \%$ formalin and embedded in paraffin according to recommended protocols. Sections were labeled and sent to the laboratory to stain with haematoxylin and eosin and examined histopathologically. Representative section was labeled and sent to laboratory to process immunohistochemically to assess P53 protein expression after the diagnosis of odontogenic cyst was made. Report of laboratory was assessed to label the positive or negative cases for P53 gene. The gold standard confirmatory investigation for histopathological and immunohistochemical evaluation was done by a single team. All the collected information was entered and analyzed using SPSS version 22.0. Quantitative representatives like age was presented by calculating mean $\pm S D$. Qualitative variables like gender and P53 expression analysis was presented as frequency and percentage.

\section{RESULTS:}

Table 1 shows according to the results of our study, $36.4 \pm 17.5$ was the mean age of all reported patients. Among which, the highest mean age shown were the cases of OKC which were $(38 \pm 17.1)$ followed by $R C$ group (32 \pm 14.8$)$. The lowest mean age shown were the cases of DC, which was $(30 \pm 19.2)$. In the present study, there were 22 males $(73.3 \%)$ and 8 females $(26.6 \%)$. Out of $10 \mathrm{DC}$ cases, 8 were males $(80 \%)$ and 2 were females $(20 \%)$. Among the reported cases of RC, 2 $(40 \%)$ were females while $3(60 \%)$ of the reported cases were of males. The percentage of males was $11(73.3 \%)$ while females were $4(26.6 \%)$ among the reported cases of OKC. Out of all reported cases, only five cases $(16.6 \%)$ were reported in maxilla while rests of the remaining twenty-five cases $(83.3 \%)$ were found in the mandible. On the other hand, mandible was the only site where all OKC and DC cases were reported. All RC cases were exclusively found in maxilla.

Table 1: Statistics of the Reported Odontogenic Cysts

\begin{tabular}{|c|c|c|c|c|c|c|}
\hline \multirow[t]{2}{*}{ Category } & \multirow[t]{2}{*}{ Numeral } & \multirow[t]{2}{*}{ Mean Age } & \multicolumn{2}{|c|}{ Gender } & \multicolumn{2}{|c|}{ Location } \\
\hline & & & Male & Female & Mandible & Maxilla \\
\hline RC & 5 & - & $3(60 \%)$ & $2(40 \%)$ & - & $5(100 \%)$ \\
\hline OKC & 15 & $38 \pm 17.1$ & $11(73.3 \%)$ & $4(26.6 \%)$ & $15(100 \%)$ & - \\
\hline DC & 10 & $30 \pm 19.2$ & $8(80 \%)$ & $2(20 \%)$ & $10(100 \%)$ & - \\
\hline Total & 30 & $36.4 \pm 17.5$ & $22(73.3 \%)$ & $8(26.6 \%)$ & $25(83.3 \%)$ & $5(16.6 \%)$ \\
\hline
\end{tabular}

RC:Radicular Cyst; OKC:Odontogenic Keratocyst; DC:Dentigerous Cyst

The most notable observation on the examined hematoxylin and eosin stained RC cases was the existence of cholesterol clefts in epithelial lining that was not regular. Stratified squamous epithelial lining was observed in two cases of DC while thick irregular corrugated stratified squamous epithelial lining was seen in all OKC cases.

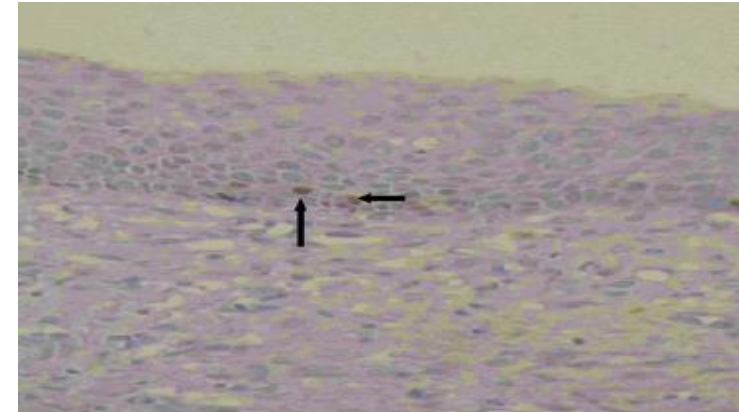

Figure 1: P53 Expression in an Odontogenic Keratocyst Case (Anti-P53, Original Magnification $x$ 250) 
Studied cyst cases showed P53 expression as brown stained nucleus of the basal and para basal layer of the epithelium. 16 cases $(53 \%)$ of the overall studied cases showed P53 in their cells out of total cases, which were 30 in our present study. P53 reactive cells were not found in RC cases however four DC cases (40\%) expressed P53 reactive cells in our present study, as shown in Table 2.

Table 2: Immunohistochemical Report of P53

\begin{tabular}{|l|c|c|c|}
\hline \multicolumn{1}{|c|}{ Category } & Numeral & $\begin{array}{c}\text { Reactive } \\
\text { Figures } \\
(\%)\end{array}$ & $\begin{array}{c}\text { Non- } \\
\text { Reactive } \\
\text { Figures } \\
(\%)\end{array}$ \\
\hline $\begin{array}{l}\text { Radicular } \\
\text { Cyst }\end{array}$ & 5 & - & $5(100 \%)$ \\
\hline $\begin{array}{l}\text { Odontogenic } \\
\text { Keratocyst }\end{array}$ & 15 & $12(80 \%)$ & $3(20 \%)$ \\
\hline $\begin{array}{l}\text { Dentigerous } \\
\text { Cyst }\end{array}$ & 10 & $4(40 \%)$ & $6(60 \%)$ \\
\hline Total & 30 & 16 & $14(46 \%)$ \\
& & $(53.3 \%)$ & \\
\hline
\end{tabular}

\section{DISCUSSION:}

Odontogenic cysts arise from the tissue responsible for tooth development and are unique to the jaws. Radicular cysts originate from epithelial lining derived from the epithelial rests of Malassez, collection of fluid under the crown follicle in association with impeded tooth eruption is associated in the formation of follicular cysts and their epithelium is originated from reduced enamel epithelium. The pathogenesis of odontogenic cysts is still unclear, the exact cause and process of epithelial proliferation are yet to be understood in few odontogenic cysts. Great variation exists in clinical and biological behavior of different odontogenic cysts that is why it is mandatory to differentiate both since the treatment and prognosis is affected by the different behavior pattern that they show $^{11}$. It is assumed that well before the tooth formation begins, epithelium of dental lamina or its remnants are responsible for derivation of OKC's epithelium that is odontogenic in origin. Oral mucosa basal cells could be the source of odontogenic cysts according to other belief. Several studies supported the reclassification of OKC and should be assumed as a benign cystic neoplasm rather than a developmental cyst. Presentation of multiple OKC's may be connected with nevoid basal cell carcinoma syndrome (NBCCS), also known as Gorlin syndrome $^{12}$. Recurrence rate of odontogenic keratocysts is higher even after surgical removal. The presence of daughter or satellite cysts that still remains even after surgical removal and multilocular nature of the cysts could be the reason of recurrence. Intrinsic growth potential in the epithelial lining of these cysts that closely relates their nature as benign neoplasm could be another reason of higher recurrence rate. P53 gene, a well-known tumor suppressor gene is located at chromosome 17 and its mutation as genetic anomaly in human neoplasms is frequently observed ${ }^{13}$. Activation of wild-type P53 protein, which acts as a DNA-binding transcription factor, is responsible for commencement of growth arrest and apoptosis as an adaptive response. Increased incidence of carcinogenesis is associated with P53 gene mutation of protein inactivation. Odontogenic keratocysts linked with the nevoid basal cell carcinoma syndrome revealed over expression of P53 but researchers comparing $\mathrm{P} 53$ and histopathological indicators in cysts of the oral cavity have shown variable results ${ }^{14}$. In normal tissues, P53 protein is associated with a very limited half-life and therefore it is difficult to detect from immunohistochemical techniques, increased stability of P53 gene is seen in mutations. P53 after its mutation becomes relatively more resistant and stable protein and its ability to accumulate make it easy to detect immunohistochemically. Binding of P53 protein to other viral proteins including EIB, HPVE6 and SV40 along with defects in protein degradation results in stabilization of P53 proteins in cells ${ }^{15}$. Our study included radicular cyst (RC), odontogenic keratocyst (OKC) and dentigerous cyst (DC) as these cysts shows multiple characteristics, presentations, and rate of occurrence within the odontogenic cystic category. The occurrence of odontogenic cysts in males was more observed as compared to females in our study, which is supported by literature in different research as well. Another research 
also supported the results of our study as being OKC and DC present more frequently in mandible while majority of RC cases are reported in maxilla ${ }^{16,17}$. Presence of P53 protein in the epithelium of basal and parabasal cells of odontogenic cysts in our study is supported by others ${ }^{18,19}$.

\section{CONCLUSION:}

Increased proliferative activity in the epithelial lining of the OKC cases in our study suggests as being the cause of elevated reappearance rate or higher frequency of the transformation into neoplasms from the OKC epithelium.

\section{LIMITATIONS:}

Due to lack of financial support available, this study could not be performed on larger scale and more patients could not be included. Funding should be provided so that these kinds of studies should be carried out at a larger scale where majority of population could be benefitted.

CONFLICT OF INTEREST: None

FUNDING SOURCES: None

\section{REFERENCES:}

1. Siwach P, Joy T, Tupkari J, Thakur A. Controversies in odontogenic tumours. Sultan Qaboos Univ Med J. $2017 ; 17(3)$ :e268.

2. da Silva LP, Serpa MS, Santana T, do Nascimento GJ, de Souza Andrade ES, Sobral AP. Clinicopathological and cell proliferation evaluation of ameloblastomas and keratocystic odontogenic tumors: a 10 year retrospective study. Eur Arch OtoRhino-Laryngol. 2017;274:1089-95.

3. Wright JM, Vered M. Update from the 4th edition of the World Health Organization classification of head and neck tumours: odontogenic and maxillofacial bone tumors. Head Neck Pathol. 2017; 11(1):68-77.

4. Al-Shimari F, Chandra S, Oda D. Adenomatoid odontogenic tumor: case series of 14 with wide range of clinical presentation. J Clin Exp Denti. $2017 ; 9(11): \mathrm{e} 1315$.
5. Garg K, Chandra S, Raj V, Fareed W, Zafar M. Molecular and genetic aspects of odontogenic tumors: a review. Iran J Basic Med Sci. 2015;18:529-36.

6. Garcia PB, Attardi LD. Illuminating P53 function in cancer with genetically engineered mouse models. Semin Cell Dev Biol. 2014;27(1):74-85.

7. Bagulkar BB, Gawande M, Chaudhary M, Gadbail AR, Patil S, Bagulkar S. XIAP and Ki-67: a correlation between antiapoptotic and proliferative marker expression in benign and malignant tumours of salivary gland: an immunohistochemical study. J Clin Diagn Res. 2015;9:EC01-EC04.

8. González-González R, MolinaFrechero N, Damian-Matsumura $P$, Salazar-Rodriguez $S$, Bologna-Molina R. Immunohistochemical expression of survivin and its relationship with cell apoptosis and proliferation in ameloblastomas. Dis Markers. 2015;2015:1-7.

9. Poswar FO, Farias LC, Fraga CA, Bambirra-Jr W, Brito-Junior M, SousaNeto MD, et al. Bioinformatics, interaction network analysis, and neural networks to characterize gene expression of radicular cyst and periapical granuloma. J Endod. 2015;41(6):877-83.

10. Dineshkumar T, Priyadharsini N, Gnanaselvi UP, Sathishkumar S, Srikanth RP, Nagarathinam $\mathrm{AE}$. Evaluation and comparison of vascular endothelial growth factor expression between ameloblastoma and keratocystic odontogenic tumor. J Int Oral Health. 2015;7(1):48-52.

11. Mascitti $M$, Santarelli A, Zizzi A, Procaccini M, Lo Muzio L, Rubini C. Expression of P73 and TRAIL in odontogenic cysts and tumors. J Oral Sci. 2016;58(4):459-64.

12. Bafna SS, Joy T, Tupkari JV, Landge JS. Dentinogenic ghost cell tumor. J Oral Maxillofac Pathol. 2016;20:163.

13. Tsuji $\mathrm{K}$, Yasuda $\mathrm{N}$, Ueda $\mathrm{M}$, Nakanishi T, Yoshida H, Oshita N, et al. Painless exophytic mass of the anterior maxillary gingiva - report of extremely rare case of peripheral dentinogenic ghost cell tumor and 
review the literature. J Oral Maxillofac Surg Med Pathol. 2017;29(4):321-3.

14. Walia C, Kashyap B, Roy S. Disorganized histomorphology: dentinogenic ghost cell tumor. J Oral Maxillofac Pathol. 2017;21:154-7.

15. Sreedhar G, Raju MV, Metta KK, Manjunath S, Shetty S, Agarwal RK. Immunohistochemical analysis of factors related to apoptosis and cellular proliferation in relation to inflammation in dentigerous and odontogenic keratocyst. J Nat Sci Biol Med. 2014;5(1):112-5.

16. Hadziabdic N, Kurtovic-Kozaric A. Oral Pathology: Gene Expression in Odontogenic Cysts. InGene Expression and Control 2018

17. Fatemeh $M$, Sepideh A, Sara BS, Nazanin M. P53 protein expression in dental follicle, dentigerous cyst, odontogenic keratocyst, and inflammatory subtypes of cysts: An immunohistochemical study. Oman Med J. 2017 May;32(3):227.

18. Kaczmarzyk T, Kisielowski K, Koszowski R, Rynkiewicz M, Gawełek $\mathrm{E}$, Babiuch $\mathrm{K}$, et al. Investigation of clinicopathological parameters and expression of COX-2, bcl-2, PCNA, and p53 in primary and recurrent sporadic odontogenic keratocysts. Clinical Oral Investi. 2018; 22(9) :3097 -106.

19. da Silva LP, Serpa MS, Santana T, do Nascimento GJ, de Souza Andrade ES, Sobral AP. Clinicopathological and cell proliferation evaluation of ameloblastomas and keratocystic odontogenic tumors: a 10 year retrospective study. European Arch of Oto - Rhino-Laryngology. 2017 1;274(2):1089 -95.

\section{CONTRIBUTORS}

1. Aqib Sohail - Concept \& Design; Final Approval

2. Aneela Amjad - Drafting Manuscript

3. Nighat Zahid - Critical Revision

4. Asad Aizaz Chatha - Data Acquisition

5. Nauman Rauf Khan - Supervision

6. Aamer lqbal - Data Analysis/Interpretation

7. Bilal Yousuf - Data Analysis/Interpretation

LICENSE: JGMDS publishes its articles under a Creative Commons Attribution Non-Commercial Share-Alike license (CC-BY-NC-SA 4.0). COPYRIGHTS: Authors retain the rights without any restrictions to freely download, print, share and disseminate the article for any lawful purpose. It includes scholarly networks such as Research Gate, Google Scholar, LinkedIn, Academia.edu, Twitter, and other academic or professional networking sites. 